\title{
PERBEDAAN HASIL BELAJAR KOGNITIF MAHASISWA BIOLOGI YANG MENGGUNAKAN MODEL PEMBELAJARAN INKUIRI DAN GROUP INVESTIGATION
}

\author{
(Studi Eksperimen pada Mahasiswa Biologi FKIP UNSIL Tahun Akademik 2014/2015 pada \\ Konsep Keaneragaman Makhluk Hidup)
}

\author{
Rita Fitriani \\ Jurusan Pendidikan Biologi FKIP Universitas Siliwangi \\ Jalan Siliwangi Nomor 24 Tlp. (0265) 323532 Fax. 323532 Tasikmalaya - 46115 \\ e-mail: tatairawan12@gmail.com
}

\begin{abstract}
The study aimed to determine the differences in cognitive learning result of biology students using inquiry and group investigation on the concept of biodevisersity. The research was comparative descriptive with one group pretest-postest design. Learning data collection techniques using pretest and posttest form and data were analyzed using independent t test. The result showed that there were differences in the biology students of learning result who use models of inquiry and group investigation and based on n-gain analysis know that inquiry learning model gives better results than group investigation.
\end{abstract}

Keywords: learning model, nquiry, group investigation, cognitive learning result

\begin{abstract}
Abstrak
Penelitian ini bertujuan untuk mengetahui perbedaan hasil belajar kognitif mahasiswa biologi yang menggunakan model pembelajaran inkuiri dan group investigation pada konsep keanekaragaman makhluk hidup. Jenis penelitian adalah deskriptif komparatif dengan rancangan one group pretestposttest design. Teknik pengumpulan data hasil belajar menggunakan pretest dan posttest dengan teknik analisis data menggunakan uji $\mathrm{t}$ independen. Hasil penelitian menunjukan bahwa ada perbedaan hasil belajar mahasiswa biologi yang menggunakan model pembelajaran inkuiri dan group investigation dan berdasarkan analisis n-gain diketahui model pembelajaran inkuiri memberikan hasil yang lebih baik dibandingkan group investigation.

Kata Kunci: Model pembelajaran, inkuiri, group investigation, hasil belajar kognitif
\end{abstract}

\section{PENDAHULUAN}

Guru menduduki posisi tertinggi dalam hal penyampaian informasi dan pengembangan karakter, mengingat guru melakukan interaksi langsung dengan peserta didik dalam pembelajaran di ruang kelas. Kualitas pendidikan yang bagus terbentuk apabila guru yang mengajar mempunyai kualitas yang bagus pula. Mendidik calon guru agar menciptakan guru yang berkualitas merupakan kunci penting permasalahan tersebut. Misi dalam melaksanakan pendidikan harus dirubah dari menciptakan lulusan hanya untuk siap kerja di dunia industry, menjadi lulusan yang siap untuk menghadapi pekerjaan yang mengutamakan kemampuan berfikir tingkat tinggi.

Berdasarkan hasil observasi hasil belajar mahasiswa biologi pada mata kuliah pengetahuan lingkungan diketahui permasalahan dalam kegiatan pembelajaran di kelas yaitu mahasiswa kurang mampu dalam mengusai suatu materi. Oleh karena itu perlu adanya proses pembelajaran yang sesuai dalam perkuliahan. Salah satu hal yang dapat digunakan yaitu dengan menerapkan model pembelajaran yang mendukung proses belajar 
mengajar mahasiswa calon guru tersebut. Menurut Ardes "Model pembelajaran mengacu pada pendekatan yang akan digunakan, termasuk di dalamnya tujuantujuan pembelajaran, lingkungan pembelajaran, dan pengelolaan kelas". Dari beragam model pembelajaran penulis tertarik meneliti model pembelajaran inkuiri dan group investigation karena kedua model pembelajaran tersebut mampu menggali informasi sebanyak mungkin mengenai suatu permasalahan yang disajikan dengan jalan penemuan dan analisis yang mendalam.

Model pembelajaran inkuiri merupakan salah satu model yang kondusif bagi pengimplementasikan pendekatan kontruktivisme. Inkuiri merupakan suatu proses untuk memperoleh informasi melalui observasi atau eksperimen untuk memecahkan suatu masalah dengan menggunakan kemampuan berfikir kritis dan logis. Hal ini sesuai dengan pendapat Sanjaya, Wina (2010) yang menyebutkan bahwa langkah-langkah pembelajaran menggunakan model inkuiri mengikuti tahapan (1) Orientasi; (2) Merumuskan Masalah; (3) Meruuskan hipotesis; (4) mengumpulkan data; (5) Menguji hipotesis; dan (6) Menarik kesimpulan. Pembelajaran menggunakan inkuiri merupakan kegiatan pembelajaran yang melibatkan secara maksimal seluruh kemampuan peserta didik untuk mencari dan menyelidiki sesuatu (benda, manusia, atau peristiwa) secara sistematis, kritis, logis, analitis sehingga mereka dapat merumuskan sendiri penemuannya dengan penuh percaya diri. Sedangkan model pembelajaran group investigation merupakan model pembelajaran yang menekankan pada partisipasi dan aktivitas peserta didik untuk mencari informasi pelajaran yang akan dipelajari melalui bahan-bahan yang tersedia, misalnya dari buku pelajaran atau melalui internet. Peserta didik dilibatkan sejak perencanaan, baik dalam menentukan topik maupun cara untuk mempelajarinya melalui investigasi. Menurut Arends (1997) pada pembelajaran dengan menggunakan group investigation para peserta didik memilih sendiri topik yang ingin dipelajari, melakukan investigasi mendalam terhadap berbagai sub topik yang telah dipilih, kemudian menyiapkan dan menyajikan suatu laporan di depan kelas secara keseluruhan. Tipe ini menuntut peserta didik memiliki kemampuan yang baik dalam berkomunikasi maupun keterampilan proses kelompok. Enam langkah model group investigation menurut Slavin (2010) yaitu (1) grouping; (2) planning; (3) investigation; (4) organizing; (5) presenting; dan (6) evaluating. Model group investigation dapat melatih peserta didik untuk menumbuhkan kemampuan berfikir mandiri. Keterlibatan peserta didik secara aktif dapat terlihat mulai dari tahap pertama sampai tahap akhir pembelajaran. Agar penelitian lebih terarah dan untuk menghindari penyimpangan yang lebih luas, maka penulis membatasi masalah sebagai berikut:

1. Penelitian dilakukan pada mahasiswa biologi semester II tahun akademik 2014/2015 FKIP Unsil;

2. Model pembelajaran yang digunakan adalah inkuiri dan group investigation;

3. Materi yang diajarkan adalah konsep keanekaragaman makhluk hidup

4. Hasil belajar yang diukur pada ranah kognitif yaitu pada dimensi pengetahaun meliputi factual, konseptual, procedural, dan metakognitif serta pada dimensi proses kognitif yang meliputi $\mathrm{C} 1$ (remembering), C2 (understanding), C3 (applying), C4 (analyzing), dan C5 (evaluating).

Berdasarkan uraian tersebut, peneliti tertarik untuk mengadakan penelitian tentang perbedaan hasil belajar kognitif mahasiswa biologi yang menggunakan model inkuri dan group investigation pada konsep keanekaragaman makhluk hidup.

\section{METODE PENELITIAN}

1. Metode penelitian

Metode yang digunakan dalam penelitian ini adalah metode deskriptif komparatif. Tujuan dari penelitian deskriptif adalah 
untuk membuat deskripsi, gambaran atau lukisan secara sistematis, factual, dan akurat mengenai fakta-fakta, sufat-sifat serta hubungan antar fenomena yang diselidiki.

2. Variabel penelitian

Variabel yang digunakan yaitu:
a. Variabel bebas yaitu model pembelajaran inkuiri dan group investigation
b. Variabel terikat yaitu hasil belajar kognitif pada konsep keanekaragaman makhluk hidup

3. Definisi operasional

Masing-masing variabel dalam penelitian ini memuat indicator-indikator yang dijelaskan melalui operasionalisasi variabel. Adapun operasionalisasi variabel dalam penelitian ini adalah:

a. Model pembelajaran inkuiri

Inkuiri dapat diartikan sebagai suatu cara penyajian pelejaran yang banyak melibatkan peserta didik dalam proses-proses mental yang lebih tinggi tingkatannya, misalnya merumuskan sendiri masalah, merancang eksperimen, melakukan eksperimen, mengumpulkan dan menganalisis data, menarik kesimpulan, mempunyai sikap-sikap objektif, jujur, hasrat ingin tahhu, terbuka, dan sebagainya.

b. Model pembelajaran group investigation

Model pembelajaran group investigation melibatkan peserta didik sejak perencanaan baik dalam seleksi topic maupun cara untuk mempelajarinya melalui invetigasi. Model ini menuntut peserta didik mempunyai kemampuan yang baik dalam berkomunikasi maupun dalam keterampilan proses kelompok. Pembagian kelompok didasarkan pada kesenangan berteman atau kesamaan minat terhadap sutau topik tertentu.

c. Hasil belajar merupakan kemampuan peserta didik setelah memperoleh pengalaman dan berinteraksi dengan lingkungannya. Hasil belajar digunakan dalam penelitian ini dibatasi pada ranah kognitif yaitu berupa skor hasil belajar pada materi keanekaragaman makhluk hidup pada dimensi pengetahuan yang meliputi factual, konseptual, procedural, dan metakognitif, serta pada dimensi proses kognitif yang meliputi $\mathrm{C} 1$ (remembering), $\mathrm{C} 2$ (understanding), C3 (applying), C4 (analyzing), dan C5 (evaluating).

4. Populasi dan sampel

a. Populasi

Populasi yang diambil yaitu seluruh kelas mahasiswa semester II jurusan pendidikan biologi tahun akadeemik 2014/2015 sebanyak 3 kelas dengan jumlah mahasiswa sebanyak 98 orang. Populasi dianggap homogen dilihat dari nilai rata-rata ujian akhir semester.

b. Sampel

Sampel yang digunakan sebanyak 2 kelas yang diambil dengan cara cluster random sampling.

5. Desain penelitian

Desain penelitian menggunakan one group petest posttest design. Dalam penelitian ini, sebelum perlakuan diberikan terlebih dahulu kelas sampel diberi pretest (tes awal) dan di akhir pembelajaran diberi posttes (tes akhir). Desai ini digunakan sesuai dengan tujuan yang hendak dicapai setelah diterapkan model pembelajaran inkuiri dan group investigation.

Rancangan:

$\begin{array}{llll}\begin{array}{l}\text { Kelas } \\ \text { eksperimen I }\end{array} & : & \mathrm{R} 1 \quad \mathrm{O} 1 \quad \mathrm{X} 1 & \mathrm{O} 2 \\ \begin{array}{l}\text { Kelas } \\ \text { eksperime II }\end{array} & : & \mathrm{R} 2 \quad \mathrm{O} 1 \quad \mathrm{X} 2 & \mathrm{O} 2 \\ \begin{array}{l}\text { Keterangan } \\ \mathrm{R}\end{array} & & & \\ \mathrm{X} 1 & : & \text { Randomnasi } & \\ \mathrm{X} 2 & : & \begin{array}{l}\text { Model inkuiri } \\ \text { investigation }\end{array} & \text { group } \\ \mathrm{O} 1 & : & \text { Prestest } & \end{array}$




\section{O2 : Posttest}

6. Teknik Pengumpulan Data

Teknik pengumpulan data menggunakan tes individual dalam bentuk multiple choice yang diberikan setelah proses belajar mengajar selesai.

7. Instrumen penelitian

Intrumen berupa tes tulis berupa multiple choice yang terdiri dari 40 soal dengan 5 option yang digunakan untuk mengukur hasil belajar kognitif mahasiswa pada konsep keanekaragaman makhuk hidup yang dibatasi pada aspek kognitif meliputi $\mathrm{C} 1$ (remembering), C2 (understanding), C3 (applying), C4 (analyzing), dan C5 (evaluating) serta pada dimensi pengetahuan meliputi factual, konseptual, procedural, dan metakognitif.

8. Uji coba instrumen

Uji validitas dilakukan pada mahasiswa kelas III B semester ke-5 tahun akademik 2014/2015 dan diperoleh 40 soal yang valid dengan reliabilitas sangat tinggi.

9. Analisis data

Langkah-langkah analisis data yang dilakukan dalam penelitian ini yaitu:

a. Uji prasyarat analisis meliputi uji normalitas menggunakna uji chi kuadrat dan uji homogenitas menggunakan uji $\mathrm{F}_{\text {maksimum }}$

b. Uji n-gain untuk melihat posisi anak di dalam kelas

c. Uji hipotesis menggunakan uji $\mathrm{t}$

10. Waktu Penelitian
a. Tempat penelitian
Penelitian dilaksankan di jurusan pendidikan biologi FKIP Universitas Siliwangi Tasikmalaya
b. Waktu penelitian
Penelitian dilakukan pada bulan Juli 2014 sampai dengan bulan November 2014

\section{HASIL DAN PEMBAHASAN}

Berdasarkan hasil analisis terhadap skor gain dengan menggunakan uji $t$ independen diketahui ada perbedaan hasil belajar mahasiswa biologi yang proses pembelajarannya menggunakan model pembelajaran inkuiri dan group investigation dengan harga $t_{\text {hitung }}=2,5$ dan $t_{\text {tabel }}=1,99$. Sedangkan rata-rata skor gain hasil belajar untuk model inkuiri 6,15 dan group investigation 4,60. Berdasarkan nilai rata-rata tersebut diketahui bahwa model inkuiri memberikan hasil yang lebih tinggi dibandingkan group investigation.

Dalam pelaksanaan pengajaran dengan menggunakan model pembelajaran inkuiri dan group investigation semua aktivitas guru dan peserta didik berdasarkan satuan mengajar dapat terlaksana. Adapun skor hasil belajar mahasiswa dapat dilihat pada diagram berikut:

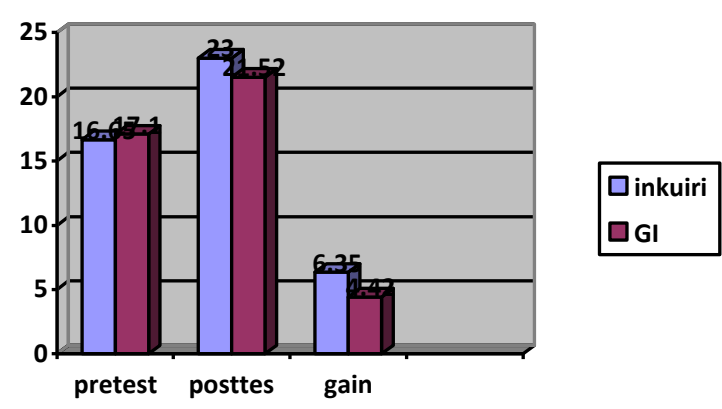

Berdasarkan diagram tersebut diketahui bahwa model pembelajaran inkuiri menunjukan hasil yang lebih baik dibandingkan group investigation, hal tersebut terlihat dari hasil pretest, posttes, maupun gain yang lebih tinggi dibandingkan group investigation. Berdasarkan analisis gain yang dinormalisasi (n-gain) juga terlihat presentase peningkatan hasil belajar dari kedua model tersebut sebagai berikut:

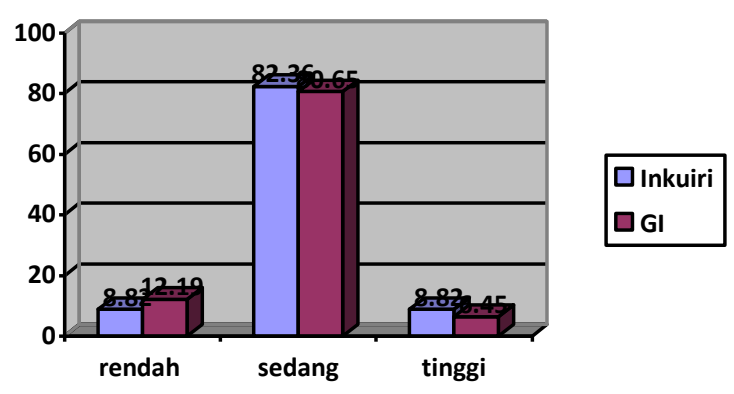

Berdasarkan diagram terlihat bahwa model 
inkuiri memiliki presentase yang lebih tinggi dalam meningkatkan hasil belajar dibandingkan group investigation. Peningkatan hasil belajar didominasi pada kategori sedang. Model inkuiri menunjukan hasil yang lebih baik pada kategori tinggi dibandingkan dengan group investigasi. Adapun perbandingan rata-rata n-gain dari kedua model dapat dilihat pada diagram berikut;

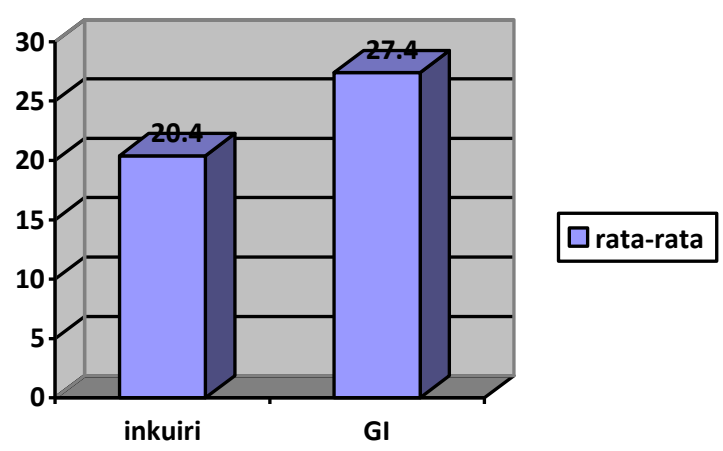

Rata-rata skor peningkatan kedua model berada pada kategori sedang, namun model inkuiri memiliki rata-rata skor yang lebih tinggi dibandingkan group investigation.

Berdasarkan uraian kedua model ternyata memberikan hasil yang sama yaitu dapat meningkatkan hasil belajar, akan tetapi berdasarkan analisis data model inkuiri memberikan hasil yang jauh lebih tinggi dibandingkan group investigation. Hal ini disebabkan penguasaan konsep biologi yang lebih baik tentunya memerlukan keterlibatan mahasiswa secara optimal dalam pembelajaran. Pembelajaran dengan inkuiri menunjukan proses pembelajaran yang terpusat pada mahasiswa. Mahasiswa diberi kesempatan untuk terlibat aktif dalam belajar baik mental, intelektual dan social emosional. Mahasiswa sebagai subjek belajar diharapkan mampu dengan optimal mengembangkan aspek kognitif, apektif, dan psikomotor secara seimbang melalui penyelidikan atau penemuannya. Kegiatan yang berlangsung melibatkan secara maksimal seluruh kemampuan mahasiswa untuk mencari dan menyelidiki secara sistematis, kritis, logis, analitis, sehingga mereka dapat merumuskan sendiri penemuannya dengan penuh percaya diri.

Mahasiswa berperan tidak sebagai penerima pelajaran melalui penjelasan dosen secara verbal, akan tetapi diarahkan untuk mampu mengatur pembelajaran dan mengembangkan pembelajarannya. Proses belajar yang dimulai dengan merumuskan masalah, mencari, meyelidiki, dan menemukan sendiri jawaban dari suatu masalah yang dipertanyakan akan memberikan kesempatan belajar yang lebih bermakna pada mahasiswa. Pembelajaran berbasis inkuiri merupakan model yang mengikuti pola metode-metode sains yang juga memberikan kesempatan kepada mahasiswa untuk belajar bermakna. Aktifitas belajar tersebut akan menimbulkan makna yang berarti dan mampu menumbuhkan sikap percaya diri pada mahasiswa. Keterampilan dan pengetahuan yang diperoleh bukan dari mengingat atau menghapal serangkat fakta, konsep atau teoro tetapi dengan menemukan dan membangun atau mengkonstruksi sendiri pengetahuan itu dan memberi makna melalui pengelaman nyata. Belajar dengan bermakna ini akan memberikan kemampuan untuk mengingat sesuatu lebih lama dan memberikan pemahaman yang lebih mendalam.

Model group investigation dalam pelaksanaanya mampu meningkatkan hasil belajar namun dengan nilai yang lebih rendah dibandingkan model inkuiri. Hal ini dapat terjadi karena mahasiswa yang belajar dengan inkuiri juga menggali informasi dari berbagai sumber mengenai materi yang dipelajari agar lebih memahami konsep awal sebelum mereka terjun langsung ke lapangan. Akibatnya semakin menguatkan pemahaman terhadap suatu konsep.

Peningkatan hasil belajar ini sesuai dengan hasil penelitian terdahulu yang dilakukan oleh beberapa peneliti diantaranya adalah Hermawati (2012) yang dalam penelitiannya menemukan perbedaan penguasaan konsep biologi antara siswa yang mengikuti model inkuiri dengan pembelajaran langsung dengan nilai rata-rata inkuiri yang lebih tinggi 
diabandingkan pembelajaran langsung. Fakta lain juga ditemukan pada penelitian Permata, (2012) bahwa model pembelajaran inkuiri dapat meningkatkan hasil belajar. Selain itu, hasil penelitian dari Bilgin (2009) menemukan prestasi belajar siswa menggunakan model inkuiri terbimbing dengan pendekatan kooperatif mengalami peningkatan dibandingkan skor pretest.

\section{SIMPULAN DAN SARAN}

1. Simpulan

Berdasarkan analisis dan pembahasan seperti yang telah dipaparkan pada bagian sebelumnya, maka dapat disimpulkan sebagai berikut:

a. Terdapat perbedaan hasil belajar kognitif mahasiswa biologi yang proses pembelajarannya menggunakan model inkuiri dan group investigation dengan harga $t_{\text {hitung }}=2,5$ dan $t_{\text {tabel }}=$ 1,99. Rata-rata skor hasil belajar yang menggunakan model inkuiri lebih tinggi dibandingkan group investigation, maka dikatakan penggunaan model inkuiri lebih baik dibandingkan dengan group investigation dalam meningkatkan hasil belajar mahasiswa.

b. Penggunaan model pembelajaran inkuiri dan group investigation berdasarkan analisis n-gain diketahui dapat meningkatkan hasil belajar mahasiswa. Peningkatan hasil belajar dengan menggunakan inkuiri lebih tinggi dibandingkan dengan group investigation.

2. Saran
a. Model pembelajaran inkuiri memberikan hasil yang lebih baik terhadap penguasaan konsep dibandingkan group investigation. Oleh karena itu, dosen disarankan untuk memahami model inkuiri dengan baik sehingga dapat mengimplementasikannya dalam pembelajaran biologi.

b. Terdapat interaksi antara model pembelajaran dengan minat belajar terrhadap hasil belajar, maka dalam memilih model pembelajaran dosen disarankan memperhatikan faktor psikologis mahasiswa yang dapat berpengaruh pada efektivitas pembelajaran

c. Bagi mahasiswa hendaknya lebih aktif dan lebih semangat dalam mengikuti proses pembelajaran biologi supaa pemahaman dan penguasaan terhadap setiap materi semakin meningkat.

\section{DAFTAR PUSTAKA}

Anderson, L.W., \& Krathwohl, D.R. (Eds). (2001). A Taxonomy for learning teaching and assesin: a revision of bloom's taxonomy of educational objectives. A bridged edition. New York:Longman.

Arikunto, Suharsimi. 2010. Prosedur penilaian suatu pendekatan praktek. Jakarta: Rineka Cipta.

Chiras, Daniel D. 2010. Environmental Science: action for a sustainable future. California : the Benjamin/cumings Pub. Co.Inc.

Dahar, Ratna Wilis. 1996. Teori-teori belajar. Jakarta: Erlangga

Jalaludin. 2013. Filsafat Ilmu Pengetahuan. Depok: Pt. Rajagrafindo Persada.

Hasan, M. Iqbal. 2002. Pokok-pokok materi metodologi penelitian dan aplikasinya. Jakarta: Ghalia Indonesia.

Iskandar, Jusman. 2012. Metode penelitian Administrasi. Bandung : Puspaga

Hamalik, Oemar. 2003. Pendekatan baru strategi belajar mengajar berdasarkan CBSA. Bandung: Sinar Baru Algesindo.

Hermawati, Ni Wayan Malik. 2012. Pengaruh model pembelajaran inkuiri terhadap penguasaan konsep biologi dan sikap ilmiah siswa SMA ditinjau dari minat belajar siswa. Jurnal pendidikan.

KBBI. 2008. Kamus Besar Bahasa Indonesia. Jakarta: Balai Pustaka. 
KLH. Undang-undang pokok pengelolaan lingkungan hidup nomor 32 tahun 2009.

Narudin, David. 2009. Pembelajaran kooperatif Group investigation (GI). [online]. Tersedia: http://akhmadsudrajat.wordpress.com/2 009/06/20/strategi-pembelajarankoopeartif-metode-group-investigation/.

Permata, Evita. 2012. Penerapan model pembelajaran inkuiri terbimbing pada pembelajara fisika SMA kelas X untuk meningkatkan prestasi belajar dan mengetahui profil ketermapilan proses sains. Jurnal pendidikan universitas pendidikan Indonesia.

Roetiyah. 2001. Strategi belajar mengajar. Jakarta: Rineka cipta.

Sugiyono. 2003. Statistik untuk penelitian. Bandung:Alfabeta.

Sugiyono. 2012. Metode penelitian kuantitatif, kualitatif dan $R \& D$. Bandung: alfabeta

Udin S. Winaputra. 2001. Model pembelajaran Inovatif. Jakarta: Universitas Terbuka.

Wina, Sanajaya. 2010. Strategi pembelajaran berorientasi standar proses pendidikan. Jakarta: Kencana

Suwartono. 2014. Dasar-dasar metodologi penelitian. Yogyakarta: Andi Yogyakarta. 